\title{
Effects of disturbance timing on community recovery in an intertidal habitat of a Korean rocky shore
}

\author{
Hyun Hee Kim, Young Wook Ko, Kwon Mo Yang, Gunhee Sung and Jeong Ha Kim* \\ Department of Biological Sciences, Sungkyunkwan University, Suwon 16419, Korea
}

Intertidal community recovery and resilience were investigated with quantitative and qualitative perspectives as a function of disturbance timing. The study was conducted in a lower intertidal rock bed of the southern coast of South Korea. Six replicates of artificial disturbance of a $50 \mathrm{~cm} \times 50 \mathrm{~cm}$ area were made by clearing all visible organisms on the rocky substrate in four seasons. Each of the seasonally cleared plots was monitored until the percent cover data reached the control plot level. There was a significant difference among disturbance timing during the recovery process in terms of speed and community components. After disturbances occurred, Ulva pertusa selectively preoccupied empty spaces quickly (in 2-4 months) and strongly (50-90\%) in all plots except for the summer plots where non-Ulva species dominated throughout the recovery period. U. pertusa acted as a very important biological variable that determined the quantitative and qualitative recovery capability of a community. The qualitative recovery of communities was rapid in summer plots where $U$. pertusa did not recruit and the community recovery rate was the lowest in winter plots where $U$. pertusa was highly recruited with a long duration of distribution. In this study, U. pertusa was a pioneer species while being a dominant species and acted as a clearly negative element in the process of qualitative recovery after disturbance. However, the negative effect of $U$. pertusa did not occur in summer plots, indicating that disturbance timing should be considered as a parameter in understanding intertidal community resilience in temperate regions with four distinct seasons.

Key Words: macroalgae; pulse disturbance; recruitment; resilience; Ulva pertusa

\section{INTRODUCTION}

Disturbance is an event that reduces a substantial amount of living biomass from a habitat due to various physical and biological causes. It often resets ecological equilibrium, temporarily increases or decreases the diversity of a community, and brings a habitat into a mosaic pattern (Bulleri et al. 2016). The cause of disturbance is different between land (fire, storms, pests, floods, etc.) and ocean (storms, pollution, oil spills, trampling, etc.), and it appears in various patterns depending on areal extent, magnitude, frequency, predictability, and turn- over rate or rotation period (Sousa 1984b). Particularly, disturbance in the rocky intertidal zones involves unpredictable and diverse causes compared to other ecosystems. In addition, changes and the intensity of physical marine environments such as waves, water temperature, and salinity add additional variables to the composition and formation of a biological community in an intertidal shore. Especially, disturbance by human influences has changed community structure in rocky intertidal zones over a long period, and the magnitude and frequency has
(1) $\$$ This is an Open Access article distributed under the terms of the Creative Commons Attribution Non-Commercial License (http://creativecommons.org/licenses/by-nc/3.0/) which permits unrestricted non-commercial use, distribution, and reproduction in any medium, provided the original work is properly cited.
Received October 22, 2017, Accepted December 7, 2017

* Corresponding Author

E-mail: jhkbio@skku.edu

Tel: +82-31-290-7009, Fax: +82-31-290-7015 
recently become higher and stronger (Addessi 1994, Milazzo et al. 2004, Long et al. 2011).

The resilience pattern of algal communities in rocky intertidal zones after disturbance is extremely dynamic. Due to the year-round availability of propagule supply and often short life span of organisms, the speed of community recovery after disturbance is faster than any other ecosystem (Sousa 1984a). Speed and pattern of a community's recovery has been reported to be related to disturbance size, timing, and early colonists (Connell and Slatyer 1977, Sousa 1984b). Also, the interactions between disturbance size and timing, geographical characteristics and the environment were reported as important factors in community resilience (Turner 1983, Farrell 1989, Kim and DeWreede 1996, Benedetti-Cecchi et al. 2003). Benedetti-Cecchi (2000) emphasized the influence of direct and indirect interactions on the recovery patterns of a rocky intertidal community through verifying various research hypotheses. Viejo (2009) compared the recovery patterns of communities in relation to disturbance along the tide level of rocky intertidal zones and concluded that the presence of physical stress and the biological characteristics of dominant species were the determining factors. Recently, Diez et al. (2009) showed that the recovery of a community in an intertidal zone was different in species composition depending on pollution levels, indicating pollution could be an another factor affecting community recovery. Therefore, understanding the role of various biological and physical factors affecting post disturbance processes is essential, but complicated (Viejo et al. 2008).

The ecological importance of disturbance timing has been suggested by multiple researchers (Peterson and Stevenson 1992, Addessi 1994, Hutchinson and Williams 2003). Recently, species diversity was reported to increase faster in the dry season than in the rainy season on a tropical rocky shore (Mayakun et al. 2010). In a temperate climate with four distinct seasons a more precise and detailed interpretation on disturbance timing may be required. The timing of a disturbance can be important since the availability of propagules is often temporally variable (Sousa 2001, Bellgrove et al. 2004), with differences in seasonal recruitment patterns influencing community structure and patterns of succession (Underwood and Anderson 1994). However, some studies showed that effects of disturbance timing were less important depending on dispersal patterns and temporal variation of dominant species in the community (Kim and DeWreede 1996, Foster et al. 2003). More recently, research on disturbance timing tend to extend their scope with relation to climate change and physical interferences (Huff 2011, Deepananda and Macusi 2012, Bernhardt and Leslie 2013). Additional studies on disturbance timing, therefore, are still required in various habitat types and geographic areas to give a habitat-specific pattern of community resilience in coastal rocky shores.

This study is the first report for Korean rocky shores of the influence of the timing of disturbance on macroalgal community recovery. We describe the patterns of community resilience in quantitative (e.g., speed of recovery) and qualitative (e.g., diversity or similarity) perspectives after seasonal experimental disturbances. Different compositions of residence species with season in the Korean habitat may provide valuable implications to disturbance ecology.

\section{MATERIALS AND METHODS}

\section{Study site}

The study site is located on a rocky shore of Jeongdo-ri, Wando-gun, Korea $\left(34^{\circ} 17^{\prime} 45^{\prime \prime} \mathrm{N}, 126^{\circ} 42^{\prime} 50^{\prime \prime} \mathrm{E}\right)$, within the Dadohae Marine National Park, designated in 1981 (Fig. 1). Wando is one of the main islands in the Korean South Sea, surrounded by many aquaculture farms producing Sargassum fusiforme, Pyropia tenera, and Haliotis discus. Nevertheless, the rocky shores of Jeongdo-ri represent a typical intertidal habitat for the southern coast of Korea. The shore of Jeongdo-ri consists mainly of a long pebble beach and gently sloping bedrock. The experiment was carried out on flat bedrock, which emerged only at low tides ( $<60 \mathrm{~cm}$ below mean sea level) (National Oceanographic Research Institute 2007). The range of tidal height in the study area was between 8 and $379 \mathrm{~cm}$ (as of March 2009). Choi and Kim (2004) reported Gelidium sp., articulate coralline algae, Grateloupia elliptica, Chondracanthus tenellus, S. fusiforme, and Chondrus ocellatus as the dominant species in the lower rocky intertidal zone of the study site. From our field observations, the six most common species were Ulva pertusa, Chondracanthus intermedius, articulate coralline algae, Gelidium sp., Chondrus ocellatus, and Chondracanthus tenellus, indicating that not much change had occurred in the community structure for about 6-7 years except for the appearance of $U$. pertusa as the most dominant species. Recently, $U$. pertusa was again reported as the most dominant species (Park et al. 2009). Invertebrate species were not at a significant amount at the tidal level of the experiment conducted, but limpets (Cellana toreuma and Acmaea palli- 


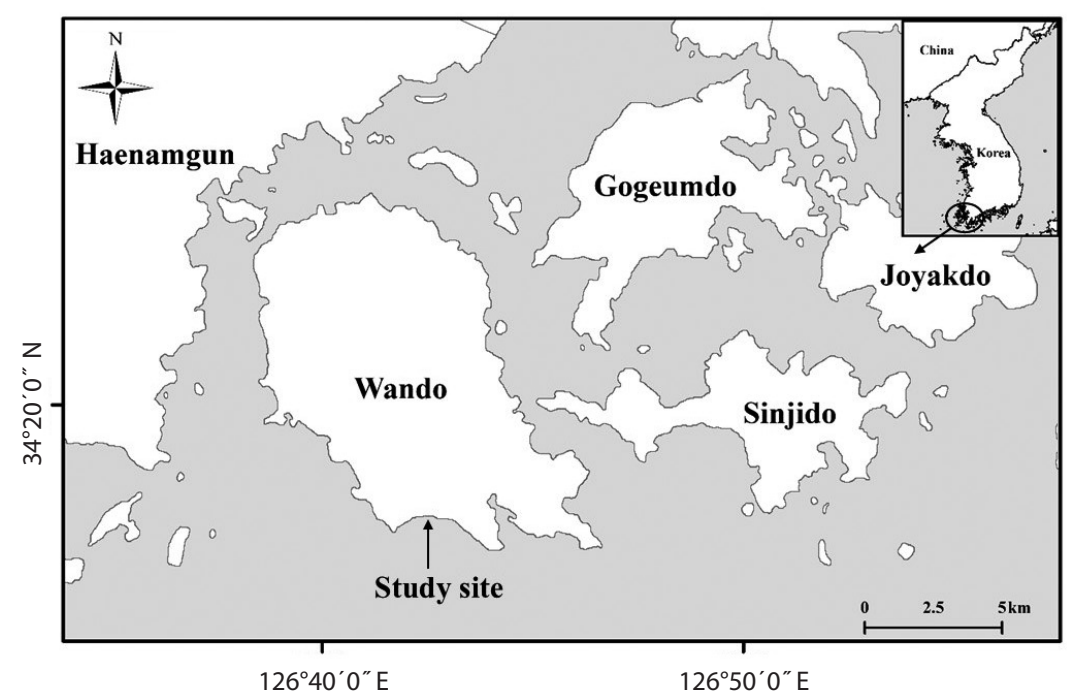

Fig. 1. The location of study site. Jeongdo-ri, Wando-gun, Korea ( $34^{\circ} 17^{\prime} 45^{\prime \prime} \mathrm{N}, 126^{\circ} 42^{\prime} 50^{\prime \prime}$ E). Rocky intertidal zones at Jeongdo-ri represents a typical species-rich habitat of southern coast of Korea.

da) and snails (Reishia clavigera, Serpulorbis imbricatus, and Serpula vermicularis) often appeared.

\section{Experimental design and data collection}

Artificial disturbance was achieved by clearing all organisms on the rock surface using a chisel and metal brush scraper. All visible organisms in $50 \mathrm{~cm} \times 50 \mathrm{~cm}$ plots were removed and rechecked carefully after the subsequent high tide, although small pieces of crustose corallines were difficult to remove. We did not use any chemicals or a fire torch to avoid possible damage to adjacent seaweeds and invertebrates. A permanent transect line $(25 \mathrm{~m}$ in length) marked in every $0.5 \mathrm{~m}$ was placed horizontally on the granite bedrock and the line position was fixed using stainless steel anchor bolts at both ends. Therefore, we could place the $50 \mathrm{~cm} \times 50 \mathrm{~cm}$ quadrat on the exact positions every sampling time. Six replicate plots $(50 \mathrm{~cm} \times$ $50 \mathrm{~cm}$ ) were randomly assigned and cleared each season, and an additional six control plots marked at the beginning of experiment and monitored throughout the study period (6 replicate plots $\times 4$ seasons, plus 6 replicate controls $=30$ plots in total). Seasonal pulse disturbances were made in July 2007 (summer), April 2008 (spring), November 2008 (autumn), and January 2009 (winter). Field observations and data collections were mostly done at 1-2 month intervals with a total 24 surveys from July 2007 to July 2010 when the communities of the treatment plots and control plots became similar.

Data were obtained by non-destructive methods in the field, and some species that were difficult to identify were collected and fixed with $5 \%$ formalin in the field and identified in the lab. Algal percent covers were estimated from subplot-based percentage counts using $5 \mathrm{~cm} \times 5 \mathrm{~cm}$ subplots made up with plastic lines in the quadrat as described in Kim et al. (2004a). In the case of relatively larger canopy algae like Sargassum thunbergii and S. fusiforme, data were counted only when the holdfast was located inside the quadrat. Digital photography, together with data estimates in the field, was sometimes used to supplement field data to obtain unbiased percent cover values.

\section{Data analyses}

In this study, community resilience was analyzed both quantitatively (\% cover recovery) and qualitatively (species diversity, similarity). One-way ANOVAs were used to compare seasonal effects with total algal cover and selected dominant species. A separate test was done at 2, 6,11 months after disturbance, because we assumed that these three time frames reflect the early, middle and later stages of community recovery in this study. Kruskal-Wallis tests were often conducted where a log transformation did not meet the parametric assumptions.

PRIMER 5 (for windows ver. 5.2.9) was used for statistical and qualitative analyses. We also used Bray-Curtis similarity analysis (Clarke and Warwick 2001) for the comparison of recovery patterns. Shannon-Wiener's diversity index was used to qualitatively evaluate community resilience (Wolda 1981). 


\section{RESULTS}

A total of 16 taxa of macroalgae were recorded during the study period including 10 Rhodophyta, 1 Chlorophyta, and 5 Phaeophyta. The major taxa of $>5 \%$ average percent cover from the all plots of treatment and control during the 3 years of study period were Ulva pertusa (13.3\%), Gelidium sp. (10.1\%), articulate coralline algae (8.3\%), Chondracanthus intermedius (7.5\%), Chondrus ocellatus (5.7\%), and Chondracanthus tenellus (5.3\%) (Table 1). The relative frequency of all 16 taxa during the observational period was 0.67 on average and three taxa, Gelidium sp., articulate coralline algae, and Chondrus ocellatus, were found at all sampling times (1.0), followed by Grateloupia elliptica (0.96), Acrosorium uncinatum (0.92), Chondracanthus tenellus (0.88), and $U$. pertusa $(0.83)$ as the high frequency species.

At each sampling time, an average of 10.7 taxa was observed, the highest being 15 taxa in April 2009 and the lowest 8 in July 2009. Seasonal abundance in percent cover of the major groups changed distinctively. U. pertusa, Gelidium sp., Chondrus ocellatus levels increased from spring and dropped after summer. On the other hand, Chondracanthus intermedius, Chondracanthus tenellus were relatively more abundant in winter than the other seasons. Articulate coralline algae did not show any seasonal patterns, but the abundance of $U$. pertusa changed

Table 1. Mean percent covers of top 5 species in the four seasonal plots

\begin{tabular}{lllc}
\hline \multirow{4}{*}{ Spring } & \multicolumn{1}{c}{ Species } & Cover (\%) \\
& 1 & Ulva pertusa & 43.4 \\
& 2 & Chondrus ocellatus & 7.3 \\
& 3 & Chondracanthus intermedius & 5.2 \\
& 4 & Gelidium sp. & 4.6 \\
& 5 & Chondracanthus tenellus & 2 \\
Summer & 1 & Chondria crassicaulis & 8.8 \\
& 2 & Chondracanthus intermedius & 8.5 \\
& 3 & Articulate coralline algae & 4.8 \\
& 4 & Chondracanthus tenellus & 4 \\
& 5 & Gelidium sp. & 3.3 \\
& 1 & Ulva pertusa & 53 \\
& 2 & Chondrus ocellatus & 9.7 \\
& 3 & Chondracanthus intermedius & 4.8 \\
& 4 & Gelidium sp. & 3.9 \\
& 5 & Articulate coralline algae & 3.9 \\
& 1 & Ulva pertusa & 65.6 \\
& 2 & Chondrus ocellatus & 4.9 \\
& 3 & Gelidium sp. & 3.4 \\
& 4 & Articulate coralline algae & 3.2 \\
& 5 & Chondracanthus intermedius & 1.6 \\
\hline
\end{tabular}

the most drastically over time among all the macroalgae (Fig. 2).

Effects of seasonal disturbance on community structure during the recovery process are shown in Fig. 3. In the plots with spring disturbance (April 2008), U. pertu$s a$ was recruited at a very fast pace and marked $74.83 \%$ cover within two months, comparable to $38.17 \%$ cover in the control plots $(\mathrm{p}<0.05)$. This pattern persisted over summer and autumn, and then levels were gradually reduced over the winter $(24.83 \%$ in the treatment plots and $0.5 \%$ in the control plots in January 2009). In the following spring (May 2009), the difference between the treatment and control disappeared $(55.67 \%$ for treatment and $47.3 \%$ for control, $\mathrm{p}>0.05$ ). The plots with summer disturbance (July 2007) showed a unique pattern from other seasonal plots. $U$. pertusa was not included in the top 5 abundant species, and instead, Chondria crassicaulis occupied the plots distinctively throughout the experimental period. Particularly, as Chondria crassicaulis started to be recruited in September 2007, they covered $13.67 \%$ in the treatment plots, compared with $1.33 \%$ in the control plots (Fig. 3). This pattern persisted until January 2008. Together with Chondria crassicaulis, Gelidium sp., and Chondracanthus tenellus were relatively abundant in the summer plots, compared to the other seasonal plots. In the autumn plots (October 2008), $U$. pertusa was selectively recruited to the treatment plots, comprising $49.5 \%$ in the treatment plots and $0.5 \%$ in the control plots in January 2009. With the seasonal bloom of $U$. pertusa in May 2009, the pattern of the difference between treatment and control was continuously maintained. It is worth noting that although the percent cover of $U$. pertusa dropped substantially in the control plots (18.17\%) in December 2009, the percent cover was still high $(63.67 \%)$ in the treatment plots, disturbed 1 year ago; this pattern persisted until May 2010 ( $\mathrm{p}<0.05$ ). Recruitment and coverage of $U$. pertusa in the treatment plots of winter disturbance (January 2009) showed an extreme case. Until March 2009, plots were bare for 2 months after disturbance, however recruitment occurred explosively in May 2009 and covered $93.83 \%$ of the treatment plots, which was about twice of the coverage in control plots (47.33\%). Although the coverage was reduced to $18.17 \%$ in the control plots in December 2009, the coverage in the treatment plots was maintained at high levels ( $>70 \%)$ until May 2010 ( $\mathrm{p}<0.05), 16$ months after disturbance. The coverage of $U$. pertusa then reduced rapidly in July 2010 to result in no difference between treatment and control (19.33 and $17.67 \%$, respectively, $\mathrm{p}>0.05$ ).

Diversity levels after disturbance were reduced and 

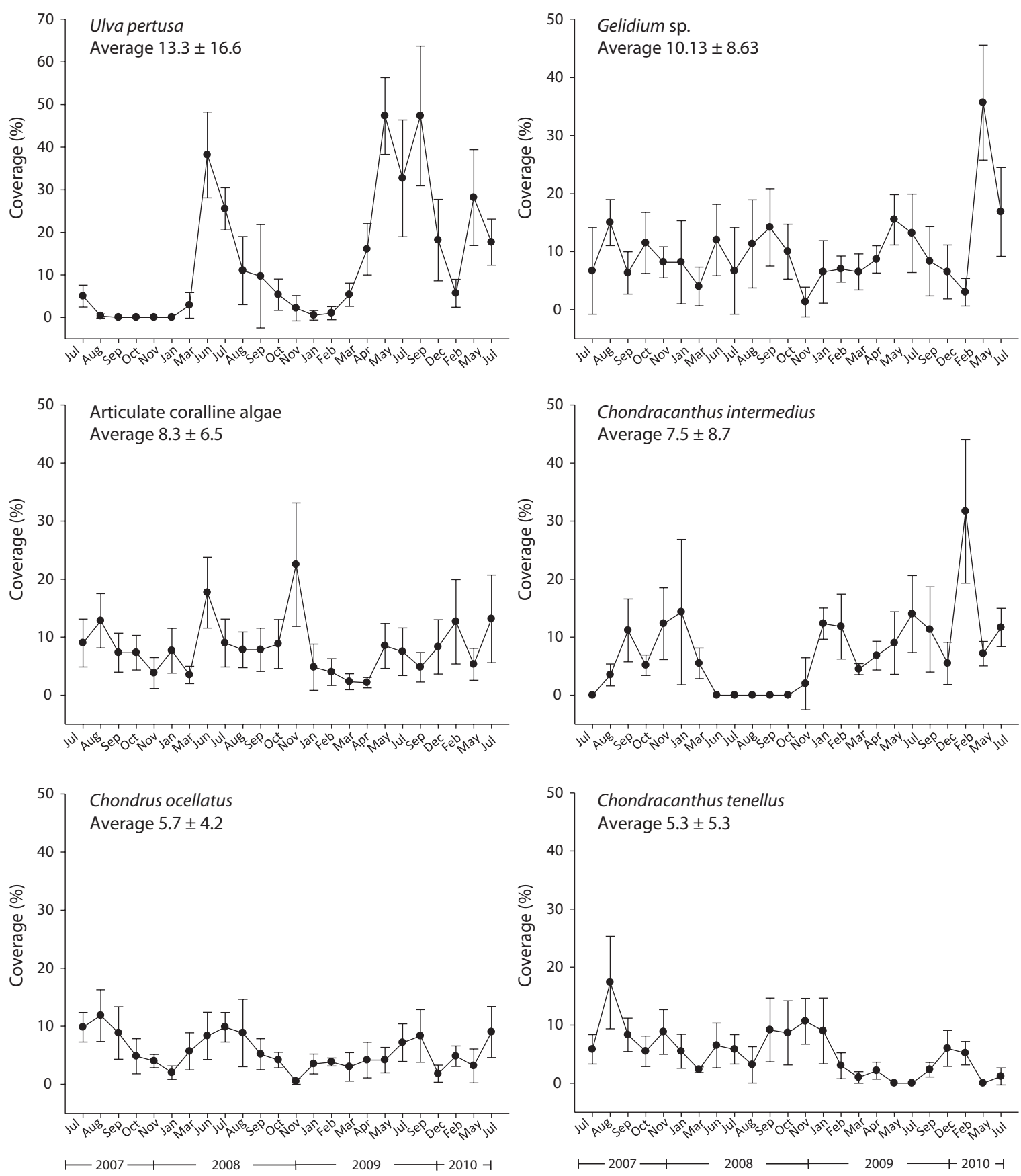

Fig. 2. Changes in percent cover for six major species during the study period.

then recovered in all seasonal plots, but the recovery patterns were different depending on disturbance timing (Fig. 4). For the spring plots (April 2008), diversity dropped greatly (1.79 to 0.28 ) and remained low until January 2009, when rapid recovery occurred to similar levels of the control plots. In January 2009, the abundance of $U$. pertusa $(24.83 \%)$, which had been recruited immediately after disturbance, started to decrease as other spe- cies such as Chondrus ocellatus and Chondracanthus intermedius increased. After January 2009, diversity levels in the spring plots showed no difference between treatment and control plots. For the summer plots (July 2007) where no dramatic appearance of a particular species like Ulva sp., diversity fluctuation was relatively small compared to other seasonal plots. However, diversity levels jumped up (1.46 to 1.92) to the pre-disturbance level in 

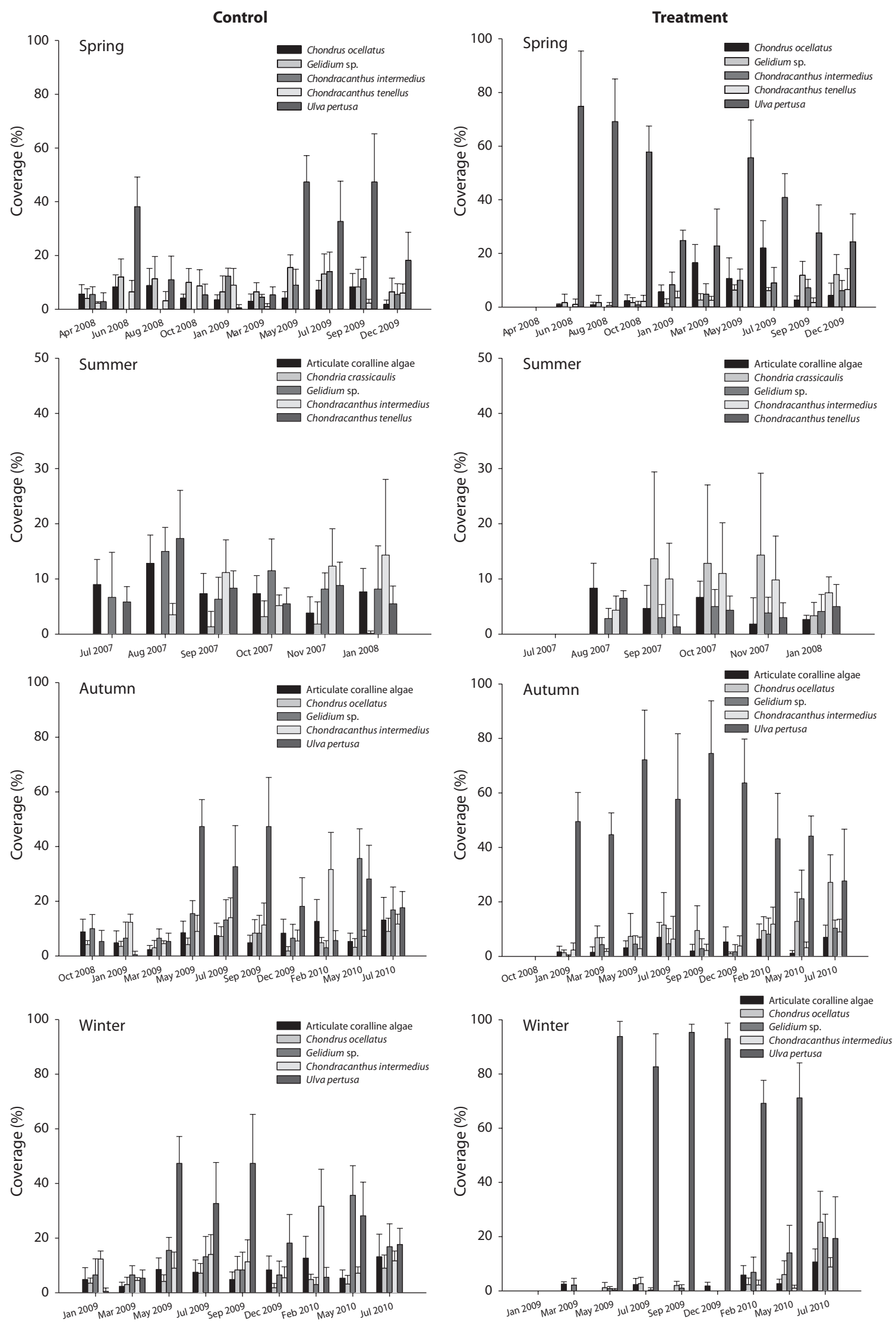

Fig. 3. Colonization patterns of major species after each seasonal disturbance. 
Kim et al. Effects of Disturbance Timing on Community Recovery
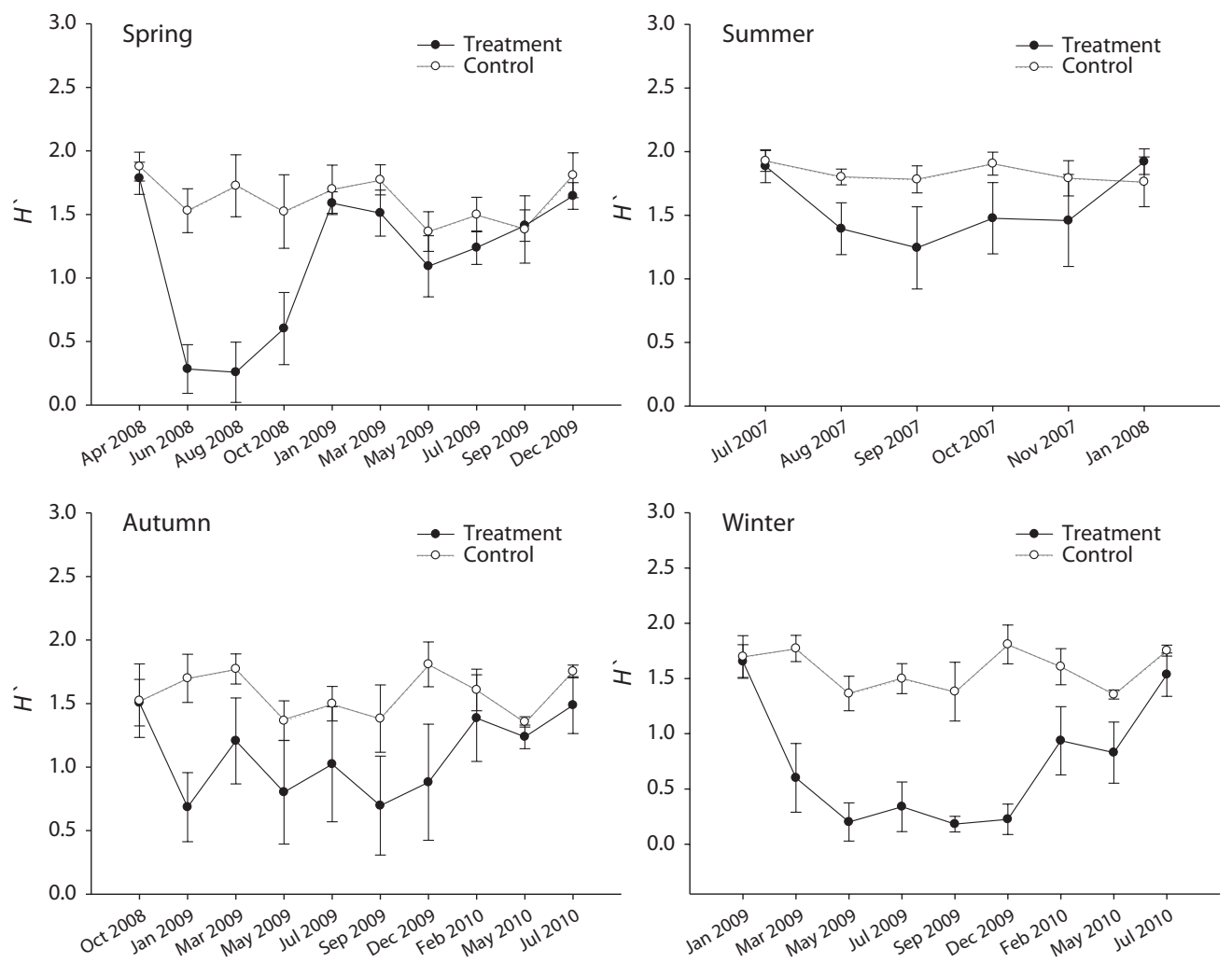

Fig. 4. Changes in species diversity level during the recovery process.
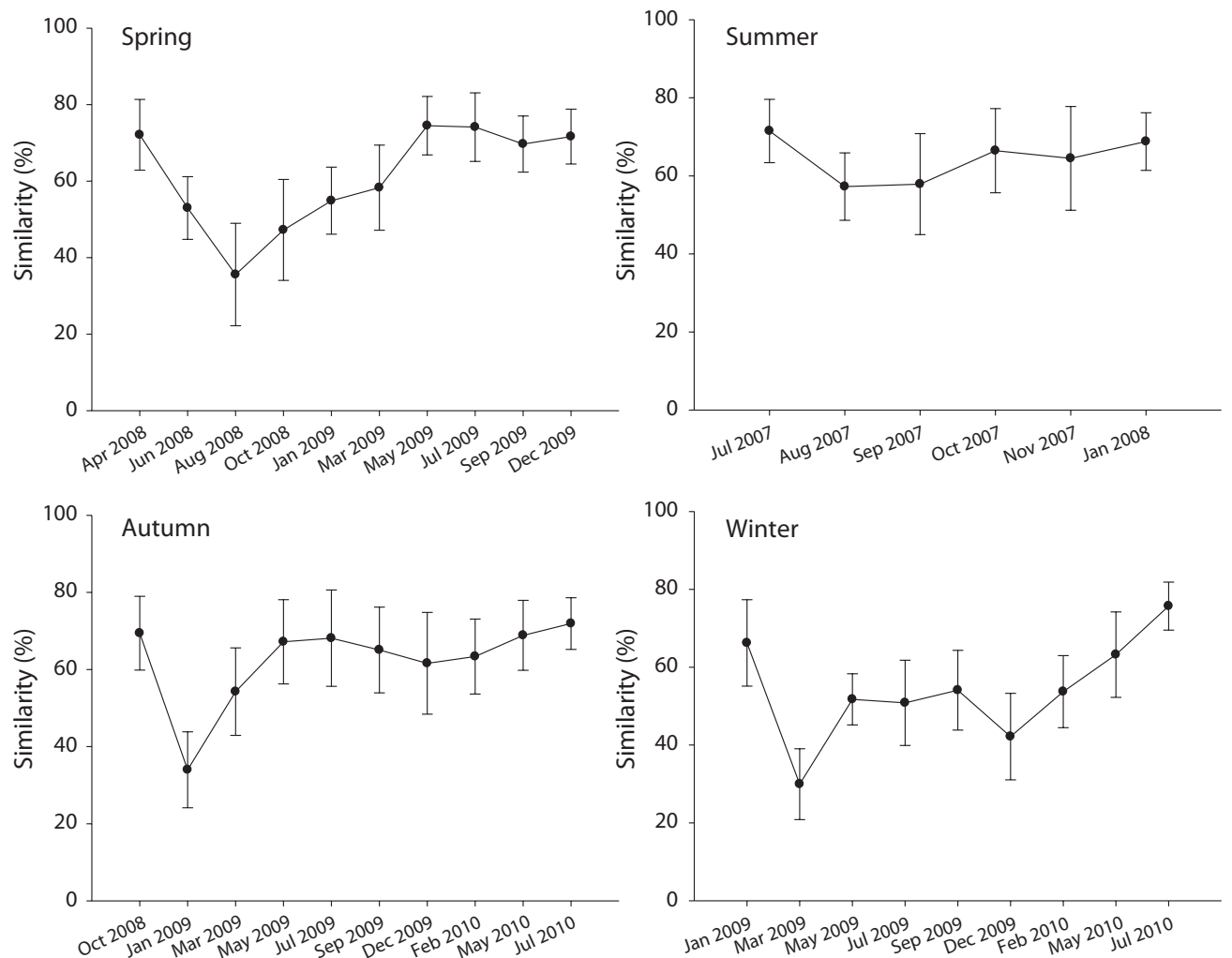

Fig. 5. Changes in similarity index during the recovery processes.

331

http://e-algae.org 
January 2008 as the percent cover of Chondria crassicaulis, which had been recruited at substantial amounts directly after disturbance, decreased. In the autumn plots (October 2008), the decreased diversity ( 1.51 to 0.68 ) after disturbance continued for an amount of time until December 2009 and fluctuated with a similar pattern to the control plots. Autumn plots began to recover 16 months after disturbance (i.e., February 2010), which timing was matched to the reduction (63.67 to $43.17 \%$ ) of $U$. pertusa coverage. Post-disturbance diversity in the autumn plots remained at a similar level as control plots, which period overlapped with low $U$. pertusa coverage. A similar pattern was observed in the winter plots (January 2009), but slightly more time (i.e., 18 months) was required for recovery (1.75 for control and 1.54 for treatment in July 2010).

Community similarity of pre-disturbance conditions of each seasonal plot was approximately $70 \%(72.11 \%$ for spring plots, $71.5 \%$ for summer plots, $69.42 \%$ for autumn plots, and $66.24 \%$ for winter plots). The similarity index between treatment and control plots showed, as expected, a reduction and gradual recovery, but the pattern was different depending on the season of disturbance. The spring plots formed the most heterogeneous community (35.59\%) at 4 months after disturbance (August 2008), and after that the similarity was gradually increased reaching $74.5 \%$ in May 2009 and maintained at around $70 \%$ afterwards. Similarity in the summer plots showed the least fluctuation, reflecting the least diversity changes, which dropped to $57.26 \%$ after disturbance (August 2008) with gradual recovery. For the autumn plots, similarity at the pre-disturbance stage was $69.42 \%$ which dropped to $33.99 \%$ after disturbance. With gradual recovery, similarity reached 67.18\% in May 2009 and remained at around $60 \%$ afterwards. In the winter plots, similarity of the postdisturbance stage started at $29.95 \%$ followed by partial recovery maintained until February 2010. After that, similarity reached 63.24\% in May 2010 and 75.7\% in July 2010, which was assumed to be complete recovery (Fig. 5).

The seasonal differences in U. pertusa, which is an important variable in the process of recovery of a community after disturbance, were compared between periods divided into the early period ( 2 months after disturbance), middle period (6 months), and later period (11 months) after disturbance. With regard to seasonal differences in the distribution of $U$. pertusa according to the periods of time after disturbance, clear seasonal differences were shown in all of the early, middle, and later periods. In particular, seasonal differences were larger in the early and later periods than in the middle period $(\mathrm{p}<0.05)$.

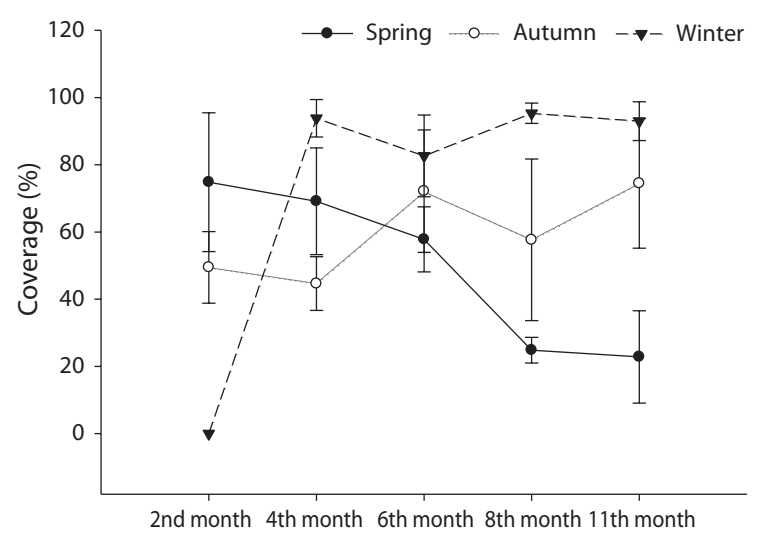

Fig. 6. Changes in the coverage of Ulva pertusa after disturbance.

Two months after the occurrence of disturbance, U. pertusa was recruited rapidly and extremely in spring plots (74.83\%) and the degree was higher than in autumn plots (49.5\%). However, in the case of winter plots, virtually no recruitment of $U$. pertusa occurred in the early period after disturbance $(\mathrm{p}<0.05)$. In the case of the middle period, $U$. pertusa was in the process of gradually decrease in the spring plots (57.83\%), maintained high coverage values $(72.17 \%)$ along with spontaneous generation in the autumn plots, and was extremely recruited to the winter plots $(82.67 \%)(p>0.05)$. In the case of the later period, $U$. pertusa coverage values decreased in the spring plots (22.83\%) and was still maintained at high levels in the autumn $(74.5 \%)$ and winter $(93 \%)$ plots $(\mathrm{p}<0.05)$ (Fig. 6$)$.

\section{DISCUSSION}

This study aimed to examine the influence of the seasonal timing of pulse disturbances on the patterns of rocky intertidal macroalgal community recovery. After disturbances occurred, $U$. pertusa preoccupied open spaces quickly and exclusively in all plots except for the summer plots where Chondria crassicaulis temporarily dominated. The patterns of community recovery thereafter seem to be directly affected by whether $U$. pertusa were recruited or not and the extent of the occupancy. That is, after disturbances, $U$. pertusa acts as a very important biological variable that determines the recovery capability of a community quantitatively and qualitatively. The rapid occupation by $U$. pertusa of even small spaces temporarily made by storms has been previously reported (Turner 1983), with rapid recruitment of Ulva sp. suppressing the settlement and recruitment of oth- 
er algae (Sousa 1979, Viejo et al. 2008). In this study, we also verified that the coverage of other species such as Chondrus ocellatus and Chondracanthus intermedius increased from the time when $U$. pertusa coverage began to decrease, indicating the strong space-preoccupying ability of $U$. pertusa. In particular, the preoccupation of bare spaces by the morphologically broad blades of $U$. pertusa acts as a negative influence of the recruitment of secondary species.

$U$. pertusa is a representative marine alga on the coasts of South Korea which is present all year round, but since unpredictable blooms occur frequently, it is not easy to evaluate the role of $U$. pertusa in intertidal community structures (Lee et al. 2000, Oh et al. 2002, Choi and Kim 2004, Kim et al. 2011) and its growth strategies to future climate conditions (Kang and Kim 2016, Kim et al. 2016). Interestingly, in this study, $U$. pertusa did not recruit to the summer plots and this is likely attributable to the natural life cycle of $U$. pertusa. Kim et al. (2004b) showed that $U$. pertusa distribution reached its peak in May and quickly decreased between July and September when temperature rose. Similarly, the coverage of Ulva sp. was reported to be the lowest in summer in Hong Kong which has a subtropical climate (Kennish et al. 1996). However, since Chondria crassicaulis was temporarily dominant after disturbances although not to a level as high as U. pertusa, the argument that the recruitment of certain species (i.e., C. crassicaulis in this study) after disturbances affects community recovery is considered valid.

Although we expected that the effects of disturbances would be offset as time passed after disturbance occurrence, the actual patterns of $U$. pertusa distribution showed clear differences among times (seasons). In particular, differences between plots are large in the early period and later period after a disturbance and these differences are attributable to the times of recruitment and periods of distribution of $U$. pertusa after the disturbance. In cases where a disturbance occurred in spring, $U$. pertusa relatively quickly recruited and continuously decreased thereafter. However, in the case of winter plots where a disturbance occurred in December, the initial recruitment of $U$. pertusa occurred later compared to spring plots and the coverage sharply increased at 4 months after the disturbance occurrence and is maintained for more than one year, so that the space preoccupation effect of $U$. pertusa is still maintained in the later period after disturbance.

The seasonal differences in the process of community recovery are noteworthy in terms of quality as well. When a disturbance occurs in the spring, the diversity of a community decreases rapidly and the recovery rate is high. However, when a disturbance occurs in autumn, the decrease in diversity is relatively smaller compared to spring and the recovery rate is very low. This is attributable to the fact that in the case of spring plots, the recruitment of other species such as Chondrus ocellatus and Gelidium sp. progressed together with that of U. pertusa in the process of community recovery, while in the case of autumn plots, $U$. pertusa recruited extremely and the period of persistence was relatively long. An interesting fact is that the pattern of similarity recovery of spring plots and autumn plots is completely different from the pattern of diversity recovery. The similarity recovery of autumn plots is approximately six months faster compared to spring plots and this is likely attributable to the community structure of the control plots. In other words, in spring plots, $U$. pertusa intensively recruited in plots where the disturbance occurred compared to control plots, while in autumn plots, high recruitment of $U$. pertusa occurred simultaneously in both treatment plots and control plots. This means that $U$. pertusa formed clearer independent communities in treatment different from control in the spring plots, and this is likely attributable to whether $U$. pertusa recruitment occurred selectively in plots where disturbances happened or occurred in the entire intertidal zone in the form of a bloom regardless of disturbance. As such, the values of diversity and similarity may be relatively different. In particular, since the results were obtained through comparison with control plots, the significance of the results may be distorted in terms of the resilience of the community. In other words, the community cannot be assumed to have recovered because the community structure is similar to control plots. In fact, similarity increased rapidly between March and May 2009 but diversity decreased. Lande (1996) and Jost et al. (2010) emphasized the necessity to take caution in analysis with ecological indexes, because of their statistical weakness. These points emphasize that interpretation of data regarding the process of community recovery should take into account of both qualitative and quantitative perspectives.

In summary, transitional communities are formed in treatment plots in the early period after a disturbance, but the communities recover to their original state (i.e., more similar to the control plots at the time) over time. As expected, the size of the decrements of diversity and similarity according to disturbance timing and recovery rates are different from plot-to-plot. The qualitative recovery of communities was rapid in summer plots where $U$. pertusa did not recruit and the community recovery rate was 
the lowest in winter plots where $U$. pertusa was extremely recruited and the duration of distribution was long. This phenomenon can be explained by the space preemption of early colonists and their sustainability. Sousa (1980) reported that species diversity increased at the beginning of the successional process before a dominant species appeared. However, in this study, that trend was not shown at all. This is likely attributable to the time difference until the dominant species is recruited. That is, in all plots except for summer plots, the recruitment of the pioneer species ( $U$. pertusa) occurred very rapidly, before any other species had an opportunity for recruitment. Viejo (2009) stated that the resilience of community was determined according to the characteristics of the dominant species, and their growth and recruitment rates. Thus our results on resilience perspectives provide supportive evidence with the $U$. pertusa space preoccupancy capability appearing in this study.

Although this study took note of the time of disturbance occurrence, many researchers emphasized the distribution and effects of herbivores on the formation of intertidal communities (Cubit 1984, Tuchman and Stevenson 1991, Navarrete 1996, Underwood 1998, Wootton 2002, Mayakun et al. 2010, Tamburello et al. 2014). However, in this study, the effect of herbivores was quite limited. Littorina sp., which is a representative herbivore, was partially distributed in the upper part of the intertidal zone, and was barely distributed in the middle and lower parts, where the experimental plots were located. Only filter feeders such as Serpula vermicularis and Serpulorbis imbricatus were present in extremely low densities. Therefore, after the pioneer species settled, there would have been very few biological factors that could possibly reduce the species. Viejo (2009) indicated that the upper part of the intertidal zone showed faster community recovery compared to other tidal levels and evaluated the reason as relatively less external stress such as herbivores. However, in this study, such results were judged applicable to the lower part of the intertidal zone as well. This is set forth as "speed-herbivory-Ulva's inhibition" mechanism in addition to the "speed-herbivory" relationship of Viejo (2009).

In the process of community recovery, the kinds and duration of distribution of initially present species such as $U$. pertusa are very important biological elements (Allison 2004). Benedetti-Cecchi (2000) reported that the space preoccupancy of filamentous algae interrupted the recruitment of later settlement species through a hypothesis testing experiment regarding intertidal bedrock succession. A recent study on the recovery patterns of a coral community in the subtidal zone also revealed that when the percent cover of the turf algae that preoccupied the space decreased, the resettlement of coral clearly increased (Emslie et al. 2008). Other studies also reported that the coralline turf algae that had been recruited after removing the dominant species had a negative influence on the recruitment of Hormosira (Bellgrove et al. 2010, Schiel and Lilley 2011). All of these studies show that competition between species occurs in the process of the resilience of a community.

In this study, $U$. pertusa was a pioneer species in the study area while being a dominant species and acted as a clearly negative element in the process of qualitative recovery after disturbance. This seems to support the typical inhibition model (Sousa 1979). However, this model cannot be applied to summer plots, and therefore, to concretely identify the effects of $U$. pertusa, comparison and tests through selective removal of target species should be conducted. Dayton (1975) experimentally verified the competition effects between species by selectively removing the canopies of macroalgae distributed in the same area. In addition, in that changes in communities involve diverse temporal and spatial variables, studies and analyses from more composite viewpoints considering differences between sea levels, seasonal and yearly variations are also necessary.

Excessive dominance by a certain species could have an equivalent effect as the occurrence of disturbances. This is also the reason why the role of $U$. pertus $a$ is emphasized in this study. Here, it is noteworthy that most of the times when the diversity of communities largely recovered include winter. This indicates that diversity is recovered when $U$. pertusa recruitment is limited. Therefore, in the case of mid-latitudinal areas where four seasons are distinctive as with South Korea, in addition to the timing of disturbance, the season that follows a disturbance is also considered to be an important environmental factor. Since physical environmental changes depending on seasons lead to the occurrence, recruitment, dominance, and settlement periods of particular species, the meaning of seasons is not at all trivial.

Intertidal zones are ecological spaces exposed to diverse physical environments, where the structures of benthic communities are changed easily by diverse events. Recently, artificial or natural disturbances to rocky intertidal zones occur more frequently and at more diverse intensities compared to the past. The effects of human leisure activities, large-scale development, and stronger storms due to climate change make the prediction of the results of disturbance more difficult. In par- 
ticular, external disturbances can cause direct damage to communities as well as opportunities for securing spaces for intertidal living dwellers with short life cycles. Therefore, understanding their spatial patterns and elucidating the mechanisms are meaningful in terms of ensuring biodiversity, and the conservation and restoration of living things.

\section{REFERENCES}

Addessi, L. 1994. Human disturbance and long-term changes on a rocky intertidal community. Ecol. Appl. 4:786-797.

Allison, G. 2004. The influence of species diversity and stress intensity on community resistance and resilience. Ecol. Monogr. 74:117-134.

Bellgrove, A., Clayton, M. N. \& Quinn, G. P. 2004. An integrated study of the temporal and spatial variation in the supply of propagules, recruitment and assemblages of intertidal macroalgae on a wave-exposed rocky coast, Victoria, Australia. J. Exp. Mar. Biol. Ecol. 310:207-225.

Bellgrove, A., McKenzie, P. F., McKenzie, J. L. \& Sfiligoj, B. J. 2010. Restoration of the habitat-forming fucoid alga Hormosira banksii at effluent-affected sites: competitive exclusion by coralline turfs. Mar. Ecol. Prog. Ser. 419:4756.

Benedetti-Cecchi, L. 2000. Predicting direct and indirect interactions during succession in a mid-littoral rocky shore assemblage. Ecol. Monogr. 70:45-72.

Benedetti-Cecchi, L., Maggi, E., Bertocci, I., Vaselli, S., Micheli, F., Osio, G. C. \& Cinelli, F. 2003. Variation in rocky shore assemblages in the northwestern Mediterranean: contrasts between islands and the mainland. J. Exp. Mar. Biol. Ecol. 293:193-215.

Bernhardt, J. R. \& Leslie, H. M. 2013. Resilience to climate change in coastal marine ecosystems. Annu. Rev. Mar. Sci. 5:371-392.

Bulleri, F., Benedetti-Cecchi, L., Jaklin, A. \& Iveša, L. 2016. Linking disturbance and resistance to invasion via changes in biodiversity: a conceptual model and an experimental test on rocky reefs. Ecol. Evol. 6:2010-2021.

Choi, T. S. \& Kim, K. Y. 2004. Spatial pattern of intertidal macroalgal assemblages associated with tidal levels. Hydrobiologia 512:49-56.

Clarke, K. R. \& Warwick, R. M. 2001. Change in marine communities: an approach to statistical analysis and interpretation. 2nd ed. PRIMER-E Ltd., Plymouth, $172 \mathrm{pp}$.

Connell, J. H. \& Slatyer, R. O. 1977. Mechanisms of succession in natural communities and their role in community stability and organization. Am. Nat. 111:1119-1144.
Cubit, J. D. 1984. Herbivory and the seasonal abundance of algae on a high intertidal rocky shore. Ecology 65:19041917.

Dayton, P. K. 1975. Experimental evaluation of ecological dominance in a rocky intertidal algal community. Ecol. Monogr. 45:137-159.

Deepananda, K. H. M. A. \& Macusi, E. D. 2012. Human disturbance on tropical rockyshore assemblages and the role of marine protected areas in reducing its impact. Philipp. Agric. Sci. 95:87-98.

Diez, I., Santolaria, A., Secilla, A. \& Gorostiaga, J. M. 2009. Recovery stages over long-term monitoring of the intertidal vegetation in the 'Abra de Bilbao' area and on the adjacent coast (N. Spain). Eur. J. Phycol. 44:1-14.

Emslie, M. J., Cheal, A. J. \& Delean, S. 2008. Recovery from disturbance of coral and reef fish communities on the Great Barrier Reef, Australia. Mar. Ecol. Prog. Ser. 371:177-190.

Farrell, T. M. 1989. Succession in a rocky intertidal community: the importance of disturbance size and position within a disturbed patch. J. Exp. Mar. Biol. Ecol. 128:5773.

Foster, M. S., Nigg, E. W., Kiguchi, L. M., Hardin, D. D. \& Pearse, J. S. 2003. Temporal variation and succession in an algal-dominated high intertidal assemblage. J. Exp. Mar. Biol. Ecol. 289:15-39.

Huff, T. M. 2011. Effects of human trampling on macro- and meiofauna communities associated with intertidal algal turfs and implications for management of protected areas on rocky shores (southern California). Mar. Ecol. 32:335-345.

Hutchinson, N. \&Williams, G. A. 2003. Disturbance and subsequent recovery of mid-shore assemblages on seasonal, tropical, rocky shores. Mar. Ecol. Prog. Ser. 249:25-38.

Jost, L., DeVries, P., Walla, T., Greeney, H., Chao, A. \& Ricotta, C. 2010. Partitioning diversity for conservation analyses. Divers. Distrib. 16:65-76.

Kang, E. J. \& Kim, K. Y. 2016. Effects of future climate conditions on photosynthesis and biochemical component of Ulva pertusa (Chlorophyta). Algae 31:49-59.

Kennish, R., Williams, G. A. \& Lee, S. Y. 1996. Algal seasonality on an exposed rocky shore in Hong Kong and the dietary implications for the herbivorous crab Grapsus albolineatus. Mar. Biol. 125:55-64.

Kim, B. J., Lee, H. J., Yum, S., Lee, H. A., Bhang, Y. J., Park, S. R., Kim, H. J. \& Kim, J. H. 2004a. A short-term response of macroalgae to potential competitor removal in a midintertidal habitat in Korea. Hydrobiologia 512:57-62.

Kim, J. H. \& DeWreede, R. E. 1996. Effects of size and season of disturbance on algal patch recovery in a rocky inter- 
tidal community. Mar. Ecol. Prog. Ser. 133:217-228.

Kim, J. H., Kang, E. J., Edwards, M. S., Lee, K., Jeong, H. J. \& Kim, K. Y. 2016. Species-specific responses of temperate macroalgae with different photosynthetic strategies to ocean acidification: a mesocosm study. Algae 31:243256.

Kim, J. H., Ko, Y. D., Kim, Y. S. \& Nam, K. W. 2011. Marine algal flora and community structure of Gogunsan islands outside the Saemangeum dike. Korean J. Environ. Ecol. 25:156-165.

Kim, K. Y., Choi, T. S., Kim, J. H., Han, T., Shin, H. W. \& Garbary, D. J. 2004b. Physiological ecology and seasonality of Ulva pertusa on a temperate rocky shore. Phycologia 43:483-492.

Lande, R. 1996. Statistics and partitioning of species diversity, and similarity among multiple communities. Oikos 76:5-13.

Lee, J. W., Oh, B. G. \& Lee, H. -B. 2000. Marine benthic algal community at Padori, west coast of Korea. Algae 15:111117.

Long, J. D., Cochrane, E. \& Dolecal, R. E. 2011. Previous disturbance enhances the negative effects of trampling on barnacles. Mar. Ecol. Prog. Ser. 437:165-173.

Mayakun, J., Kim, J. H. \& Prathep, A. 2010. Effects of herbivory and the season of disturbance on algal succession in a tropical intertidal shore, Phuket, Thailand. Phycol. Res. 58:88-96.

Milazzo, M., Badalamenti, F., Riggio, S. \& Chemello, R. 2004. Patterns of algal recovery and small-scale effects of canopy removal as a result of human trampling on a Mediterranean rocky shallow community. Biol. Conserv. 117:191-202.

National Oceanographic Research Institute. 2007. 2008 Tide tables (coast of Korea). Korea Ministry of Oceans and Fisheries, Publication No. 510. National Oceanographic Research Institute, Incheon, 367 pp.

Navarrete, S. A. 1996. Variable predation: effects of whelks on a mid-intertidal successional community. Ecol. Monogr. 66:301-321.

Oh, B. G., Lee, J. W. \& Lee, H. B. 2002. A summer marine benthic algal flora and community of uninhabited islands in Haenamgun, southern coast of Korea. J. Korean Fish. Soc. 35:57-63.

Park, C. S., Lee, K. W., Cho, Y. S., Kim, G. B., Oh, J. G. \& Hwang, E. K. 2009. Summer algal flora of Dadohae National Park, southwestern coast of Korea. Korean J. Environ. Biol. 27:252-260.

Peterson, C. G. \& Stevenson, R. J. 1992. Resistance and resilience of lotic algal communities: importance of disturbance timing and current. Ecology 73:1445-1461.
Schiel, D. R. \& Lilley, S. A. 2011. Impacts and negative feedbacks in community recovery over eight years following removal of habitat-forming macroalgae. J. Exp. Mar. Biol. Ecol. 407:108-115.

Sousa, W. P. 1979. Experimental investigations of disturbance and ecological succession in a rocky intertidal algal community. Ecol. Monogr. 49:227-254.

Sousa, W. P. 1980. The responses of a community to disturbance: the importance of successional age and species' life histories. Oecologia 45:72-81.

Sousa, W. P. 1984a. Intertidal mosaics: patch size, propagule availability, and spatially variable patterns of succession. Ecology 65:1918-1935.

Sousa, W. P. 1984b. The role of disturbance in natural communities. Annu. Rev. Ecol. Syst. 15:353-391.

Sousa, W. P. 2001. Natural disturbance and the dynamics of marine benthic communities. In Bertness, M. D., Gaines, S. D. \& Hay, M. E. (Eds.) Marine Community Ecology. Sinauer Associates, Sunderland, MA, pp. 85-130.

Tamburello, L., Bulleri, F., Balata, D. \& Benedetti-Cecchi, L. 2014. The role of overgrazing and anthropogenic disturbance in shaping spatial patterns of distribution of an invasive seaweed. J. Appl. Ecol. 51:406-414.

Tuchman, N. C. \& Stevenson, R. J. 1991. Effects of selective grazing by snails on benthic algal succession. J. N. Am. Benthol. Soc. 10:430-443.

Turner, T. 1983. Complexity of early and middle successional stages in a rocky intertidal surfgrass community. Oecologia 60:56-65.

Underwood, A. J. 1998. Grazing and disturbance: an experimental analysis of patchiness in recovery from a severe storm by the intertidal alga Hormosira banksii on rocky shores in New South Wales. J. Exp. Mar. Biol. Ecol. 231:291-306.

Underwood, A. J. \& Anderson, M. J. 1994. Seasonal and temporal aspects of recruitment and succession in an intertidal estuarine fouling assemblage. J. Mar. Biol. Assoc. UK. 74:563-584.

Viejo, R. M. 2009. Resilience in intertidal rocky shore assemblages across the stress gradient created by emersion times. Mar. Ecol. Prog. Ser. 390:55-65.

Viejo, R. M., Arenas, F., Fernández, C. \& Gómez, M. 2008. Mechanisms of succession along the emersion gradient in intertidal rocky shore assemblages. Oikos 117:376389.

Wolda, H. 1981. Similarity indices, sample size and diversity. Oecologia 50:296-302.

Wootton, J. T. 2002. Mechanisms of successional dynamics: consumers and the rise and fall of species dominance. Ecol. Res. 17:249-260. 